\title{
In Vitro Antitumor Activity of Alkylaminoguaiazulenes
}

\author{
MARI UEHARA ${ }^{1 *}$, HIMAWARI MINEMURA ${ }^{1 *}$, TSUNENORI OHNO ${ }^{1}$, MASASHI HASHIMOTO $^{1}$, \\ HIDETSUGU WAKABAYASHI $^{1}$, NORIYUKI OKUDAIRA ${ }^{2}$ and HIROSHI SAKAGAMI ${ }^{3}$ \\ ${ }^{1}$ Faculty of Science, Josai University, Saitama, Japan; \\ ${ }^{2}$ Division of Pharmacology, Meikai University School of Dentistry, Saitama, Japan; \\ ${ }^{3}$ Meikai University Research Institute of Odontology (M-RIO), Saitama, Japan
}

\begin{abstract}
Background/Aim: Guaiazulene (1,4-dimethyl-7isopropylazulene) is present in several essential oils of medicinal and aromatic plants. There exist few studies that investigated the anticancer activity of guaiazulenes. We investigated the relative cytotoxicity of 10 alkylaminoguaiazulene derivatives towards both cancer and normal cells. Materials and Methods: Cytotoxicity towards four human oral squamous cell carcinoma (OSCC) cell lines and five types of human normal oral cells (gingival fibroblasts, periodontal ligament fibroblasts, pulp cells and keratinocytes, gingival epithelial progenitors) was determined by the 3-(4,5-dimethylthiazol-2-yl)-2,5diphenyltetrazolium bromide (MTT) method. Tumor specificity (TS) was evaluated as the ratio of the mean $50 \%$ cytotoxic concentration against normal oral cells to that against OSCC cell lines. Apoptosis-inducing activity was evaluated by cleavage of poly ADP-ribose polymerase and caspsase-3 with western blot analysis. Results: Validity of the present TS measurement method was confirmed using methotrexate. With increasing length of the alkyl group of alkylaminoguaiazulene derivatives, cytotoxicity increased. Introduction of oxygen, nitrogen or sulfur atom into the alkyl group slightly reduced cytotoxicity. Most compounds had very low TS, no synergistic action with methotrexate and doxorubicin, nor did they induce apoptosis of OSCC cells. On the other hand, compound [10], containing a morpholino group, induced apoptosis of OSCC cells.
\end{abstract}

This article is freely accessible online.

*These Authors contributed equally to this work.

Correspondence to: Hidetsugu Wakabayashi, Faculty of Science, Josai University, 1-1 Keyakidai, Sakado, Saitama 350-0295, Japan. Tel: +81 492717959, Fax: +81 492717985, e-mail: hwaka@josai.ac.jp/ sakagami@dent.meikai.ac.jp

Key Words: Alkylaminoguaiazulene, alkylation, morpholine backbone, cytotoxicity, tumor specificity, apoptosis.
Conclusion: The cytotoxicity of alkylaminoguaiazulenes is not always coupled with TS and apoptosis-inducing activity.

Guaiazulene (1,4-dimethyl-7-isopropylazulene), present in several essential oils of medicinal and aromatic plants, is widely used as a natural ingredient in many healthcare products. There are limited numbers of studies that have investigated the cytotoxicity of guiazulene. Guaiazulenes are highly toxic to human leukemia cell lines (HL-60. K562) (1), freshly prepared rat neuron cells and neuroblastoma cell lines (2), and human gingival fibroblasts (3); toxicity against fibroblasts was partially reversible by UV irradiation (3). We previously reported that methyl 7-isopropyl-2methoxyazulene-1-carboxylate had higher tumor-specific cytotoxicity than azulene and guaiazulene, and induced apoptosis of HL-60 cells, possibly by non-radical-mediated mechanism (4).

In order to search for tumor-selective guaiazulene derivatives, we synthesized 10 alkylaminoguaiazulenes (Figure 1) and investigated their anticancer activity. Validation of apoptosis research seems to derive from reports that apoptosis induced by anticancer agents is also detected in clinical cancer tissue (5). Therefore, we also investigated apoptosis induction by these compounds.

\section{Materials and Methods}

Materials. The following chemicals and reagents were obtained from the indicated companies: Dulbecco's modified Eagle's medium (DMEM) from GIBCO BRL, Grand Island, NY, USA; fetal bovine serum (FBS), 3-(4,5-dimethylthiazol-2-yl)-2,5-diphenyltetrazolium bromide (MTT), doxorubicin-HCl from Sigma-Aldrich Inc., St. Louis, MO, USA; dimethyl sulfoxide (DMSO) from Wako Pure Chem. Ind., Osaka, Japan; methotrexate from Nacalai Tesque, Inc., Kyoto, Japan. Culture plastic dishes and plates (96-well) were purchased from Becton Dickinson (Franklin Lakes, NJ, USA). Protease and phosphatase inhibitors were purchased from Roche Diagnostics (Tokyo, Japan). Antibodies against cleaved caspase-3 (Cell Signaling Technology Inc., Beverly, MD, USA), poly ADPribose polymerase (PARP; Cell Signaling Technology Inc.) and glyceraldehyde 3-phosphate dehydrogenase (GAPDH; Trevigen, 


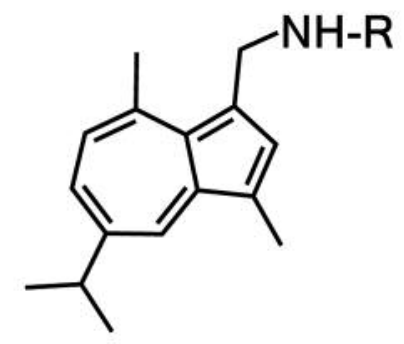

1: $\mathrm{R}=\left(\mathrm{CH}_{2}\right)_{2} \mathrm{NH}_{2}$

2: $\mathrm{R}=\left(\mathrm{CH}_{2}\right)_{3} \mathrm{NH}_{2}$

3: $\mathrm{R}=\left(\mathrm{CH}_{2}\right)_{4} \mathrm{NH}_{2}$

4: $\mathrm{R}=\left(\mathrm{CH}_{2}\right)_{5} \mathrm{NH}_{2}$

5: $\mathrm{R}=\left(\mathrm{CH}_{2}\right)_{6} \mathrm{NH}_{2}$

6: $\mathrm{R}=\left(\mathrm{CH}_{2}\right)_{3} \mathrm{O}\left(\mathrm{CH}_{2}\right)_{3} \mathrm{NH}_{2}$

7: $\mathrm{R}=\left(\mathrm{CH}_{2}\right)_{3} \mathrm{~N}\left(\mathrm{CH}_{3}\right)_{2}$

8: $\mathrm{R}=\left(\mathrm{CH}_{2}\right)_{2} \mathrm{O}\left(\mathrm{CH}_{2}\right)_{2} \mathrm{O}\left(\mathrm{CH}_{2}\right)_{2} \mathrm{NH}_{2}$

9: $\mathrm{R}=\left(\mathrm{CH}_{2}\right)_{2} \mathrm{~S}\left(\mathrm{CH}_{2}\right)_{2} \mathrm{NH}_{2}$

10: $\mathrm{R}={ }_{\mathrm{O}}$

Figure 1. Structure of alkylaminoguaiazulenes.

Gaithersburg, MD, USA) were used as primary antibodies. As secondary antibodies, horseradish peroxidase-conjugated $\alpha$-rabbit IgG (DAKO, Tokyo, Japan) antibodies were used.

Synthesis of alkylaminoguaiazulenes. 3-(2-Aminoethylamino)methylguaiazulene [1], 3-(3-aminopropylamino)methylguaiazulene [2], 3-(4aminobutylamino)methylguaiazulene [3], 3-(5-aminopentylamino) methylguaiazulene [4], 3-(6-aminohexylamino)methylguaiazulene [5], 3-(3-(3-aminopropoxy)propylamino)methylguaiazulene [6], 3-(3- $N, \mathrm{~N}$ dimethylaminopropylamino)methylguaiazulene [7], 3-(2-(2-(2-aminoethoxy)ethoxy)ethyl)amino)methylguaiazulene [8], 3-(2-(2-aminoethylthio)ethylamino)methylguaiazulene [9], 3-(2-morpholinoethylamino)methylguaiazulene [10] were synthesized according to previous reports (6-8). All compounds were dissolved in DMSO at $40 \mathrm{mM}$ and stored at $-20^{\circ} \mathrm{C}$ before use.

Cell culture. Human gingival fibroblast (HGF), periodontal ligament fibroblast (HPLF) and pulp (HPC) cells, established from the first premolar tooth extracted from the lower jaw of a 12-year-old girl (9), and OSCC cell lines (Ca9-22, HSC-2, HSC-3, HSC-4), purchased from Riken Cell Bank, Tsukuba, Japan, were cultured at $37^{\circ} \mathrm{C}$ in DMEM supplemented with $10 \%$ heat-inactivated FBS, 100 units $/ \mathrm{ml}$, penicillin $\mathrm{G}$ and $100 \mu \mathrm{g} / \mathrm{ml}$ streptomycin sulfate under a humidified atmosphere with $5 \% \mathrm{CO}_{2}$. Human oral keratinocyte (HOK) cells (purchased from COSMO BIO Co/Ltd., Tokyo, Japan) were cultured in oral keratinocyte growth supplement (OKGS), and human primary gingival epithelial (HGEP) cells (purchased from

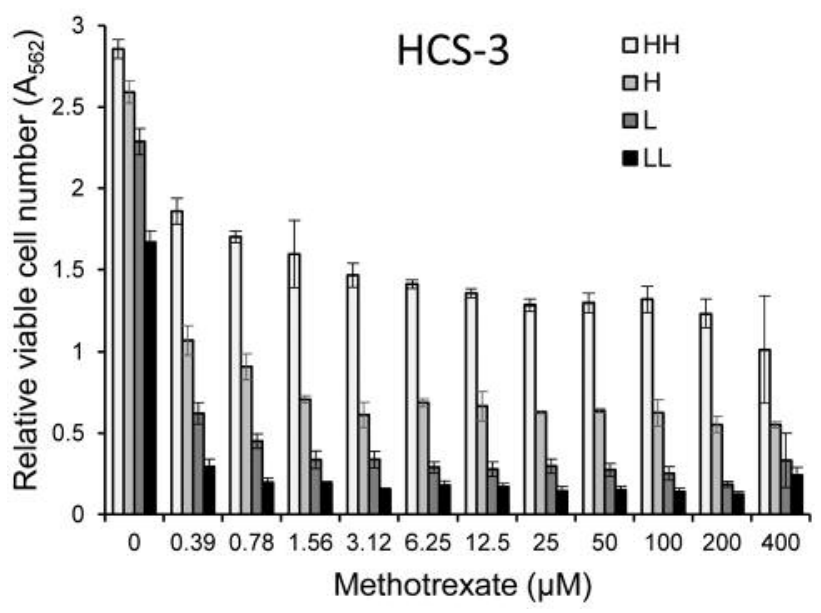

Figure 2. Dose-response curve of cytotoxicity induction by methotrexate in cells inoculated at different density. HSC-3 cells were inoculated at 1, 2, 4 or $8 \times 10^{3} /$ well in 96-microwell plate [very low (LL), low (L), high $(\mathrm{H})$ or very high $(\mathrm{HH})$ cell density] and incubated for $48 \mathrm{~h}$ to allow the complete cell attachment. Cells were then exposed for $48 \mathrm{~h}$ to the indicated concentrations of methotrexate to determine the viable cell number at $562 \mathrm{~nm}$ by MTT method. Each value represents mean \pm S.D of quadruplicate determinations.

CELLnTEC Advanced Cell Systems AG, Bern, Switzerland) were grown in CnT-PR medium (CELLnTEC) (10-12). HGF, HPLF and HPC at 12-20 population doubling level, and HOK and HGEP at 7-11 population doubling level were used in the present study.

Assay for cytotoxic activity. Cells were inoculated at $2 \times 10^{3}$ cells $/ 0.1$ $\mathrm{ml}$ in a 96-microwell plate (Becton Dickinson Labware), since inoculation of cells at higher cell density resulted in inaccurate estimation of viable cell number (Figure 2). After $48 \mathrm{~h}$, the medium was removed by suction with an aspirator and replaced with $0.1 \mathrm{ml}$ of fresh medium containing different concentrations of the test compounds. Control cells were treated with the same amounts of DMSO present in each diluent solution. Cells were incubated for 48 $\mathrm{h}$ and the relative viable cell number was then determined by the MTT method. In brief, the treated cells were incubated for another $2 \mathrm{~h}$ in fresh culture medium containing $0.2 \mathrm{mg} / \mathrm{ml}$ MTT. Cells were then lysed with $0.1 \mathrm{ml}$ of DMSO and the absorbance at $562 \mathrm{~nm}$ of the cell lysate was determined using a microplate reader (Sunrise Rainbow RC-R; TECAN, Mannedorf, Switzerland). The 50\% cytotoxic concentration $\left(\mathrm{CC}_{50}\right)$ was determined from the doseresponse curve of triplicate or quadruplicate samples.

Calculation of tumor-selectivity index (TS). TS was calculated using the following equation: $\mathrm{TS}=$ mean $\mathrm{CC}_{50}$ against three normal oral cells/mean $\mathrm{CC}_{50}$ against OSCC cell lines [(D/B) in Table I]. Since both Ca9-22 and HGF cells were derived from gingival tissue (13), the relative sensitivity of these cells was also compared [(C/A) in Table I]. We did not use human normal oral keratinocytes for tumor-specificity assay, since many anticancer drugs showed potent cytotoxicity against normal keratinocytes by inducing apoptosis (14). 
Table I. Time-dependent induction of cytotoxicity by methotrexate. Each value represents the mean from triplicate assays.

\begin{tabular}{|c|c|c|c|c|c|}
\hline & & \multicolumn{4}{|c|}{$\mathrm{CC}_{50}$ of methotrexate $(\mu \mathrm{M})$} \\
\hline & & $24 \mathrm{~h}$ & $48 \mathrm{~h}$ & $72 \mathrm{~h}$ & $96 \mathrm{~h}$ \\
\hline \multirow[t]{4}{*}{ Human oral squamous cell carcinoma cells } & $\mathrm{Ca} 9-22$ & $>400$ & 230 & $<6.3$ & $<6.3$ \\
\hline & HSC-2 & $>400$ & 253 & $<6.3$ & $<6.3$ \\
\hline & HSC-3 & $>400$ & $<6.3$ & $<6.3$ & $<6.3$ \\
\hline & HSC-4 & $>400$ & $<6.3$ & $<6.3$ & $<6.3$ \\
\hline \multirow[t]{2}{*}{ Human normal oral epithelial cells } & HOK & $>400$ & 291 & 50 & 302 \\
\hline & HGEP & $>400$ & $<6.3$ & $<6.3$ & $<6.3$ \\
\hline \multirow[t]{3}{*}{ Human normal oral messenchymal cells } & HGF & $>400$ & $>400$ & 249 & $>400$ \\
\hline & HPLF & $>400$ & $>400$ & $>400$ & $>400$ \\
\hline & HPC & $>400$ & $>400$ & $>400$ & $>400$ \\
\hline
\end{tabular}

HOK, Human oral keratinocytes; HGEP: primary human gingival epithelial cells; HGF: human gingival fibroblasts; HPLF: periodontal ligament fibroblasts; HPC: pulp cells; $\mathrm{CC}_{50} .50 \%$ cytotoxic concentration.

Table II. Cytotoxicity of alkylaminoguaiazulenes and doxorubicin against human oral squamous cell carcinoma (OSCC) cell lines and human normal oral cells.

\begin{tabular}{|c|c|c|c|c|c|c|c|c|c|c|c|}
\hline \multirow{3}{*}{ Compound } & \multicolumn{5}{|c|}{ Human OSCC cell lines } & \multicolumn{4}{|c|}{ Human normal oral cells } & \multirow{2}{*}{\multicolumn{2}{|c|}{ TS }} \\
\hline & $\mathrm{Ca} 9-22$ & HSC-2 & HCS-3 & HSC-4 & Mean & HGF & HPLF & HPC & Mean & & \\
\hline & (A) & & & & (B) & (C) & & & (D) & $(\mathrm{D} / \mathrm{B})$ & $(\mathrm{C} / \mathrm{A})$ \\
\hline 1 & 11.11 & 9.28 & 11.71 & 10.52 & 10.65 & 25.44 & 15.26 & 18.56 & 19.75 & 1.85 & 2.29 \\
\hline 2 & 10.92 & 8.38 & 7.13 & 6.49 & 8.23 & 13.91 & 25.56 & 10.21 & 16.56 & 2.01 & 1.27 \\
\hline 3 & 4.52 & 3.87 & 4.15 & 3.74 & 4.07 & 5.11 & 4.1 & 4.56 & 4.59 & 1.13 & 1.13 \\
\hline 4 & 2.66 & 2.13 & 2.04 & 1.95 & 2.19 & 3.02 & 2.36 & 2.27 & 2.55 & 1.16 & 1.14 \\
\hline 5 & 1.91 & 2.19 & 1.43 & 1.32 & 1.71 & 2.36 & 1.34 & 1.68 & 1.79 & 1.05 & 1.23 \\
\hline 6 & 4.26 & 3.98 & 3.13 & 3.3 & 3.67 & 4.81 & 3.28 & 3.67 & 3.92 & 1.07 & 1.13 \\
\hline 7 & 9.64 & 7.3 & 6.27 & 7.02 & 7.56 & 11.51 & 9.16 & 10.51 & 10.39 & 1.38 & 1.19 \\
\hline 8 & 8.16 & 10.26 & 8.93 & 8.36 & 8.93 & 17.52 & 13.87 & 13.88 & 15.09 & 1.69 & 2.15 \\
\hline 9 & 4.79 & 4.9 & 5.2 & 4.26 & 4.78 & 7.25 & 5.85 & 6.67 & 6.59 & 1.38 & 1.51 \\
\hline 10 & 14.88 & 20.72 & 13.75 & 11.82 & 15.29 & 38.84 & 30.5 & 37.16 & 35.5 & 2.32 & 2.61 \\
\hline DXR & 0.06 & 0.04 & 0.03 & - & 0.04 & 0.54 & - & 1.43 & 0.99 & 22.81 & 9.21 \\
\hline
\end{tabular}

Each value represents the mean from triplicate assays. Ca9-22, HSC-2, HSC-3 and HSC-4: Oral squamous cell carcinoma cell lines; HGF: human gingival fibroblasts; HPLF: periodontal ligament fibroblasts; HPC: pulp cells; $\mathrm{CC}_{50} .50 \%$ cytotoxic concentration; DXR: doxorubicin-HCl.

Western blot analysis. The treated with cells were washed with phosphate-buffered saline and re-suspended in $50 \mathrm{mM}$ Tris- $\mathrm{HCl}(\mathrm{pH}$ 7.6), $150 \mathrm{mM} \mathrm{NaCl}, 1 \mathrm{mM}$ EDTA, $0.1 \%$ sodium dodecyl sulfate, $0.5 \%$ deoxycholic acid, $1 \% \mathrm{NP}-40$ and protease inhibitors (RIPA buffer). After ultrasonication using Bioruptor (UCD-250; Cosmo Bio) for $12.5 \mathrm{~min}$ (10 s on, $20 \mathrm{~s}$ off) at the middle level of output $(250 \mathrm{~W})$ at $4^{\circ} \mathrm{C}$, the soluble cellular extracts were recovered after centrifugation for $10 \mathrm{~min}$ at $16,000 \times \mathrm{g}$. The protein concentration of each sample was determined using BCA Protein Assay Reagent Kit (Thermo Fisher Scientific, Waltham, MA, USA) and cell extracts were subjected to western blot analysis. The blots were probed with the primary antibody followed by a horseradish peroxidase-conjugated secondary antibody. The immune complexes were visualized using Pierce Western Blotting Substrate Plus
(Thermo Fisher Scientific). Western blot results were documented and quantified using ImageQuant LAS 500 (GE Healthcare, Tokyo, Japan) (15).

Statistical treatment. Each experimental value is expressed as the mean \pm standard deviation (SD) of triplicate or quadruplicate determinations. CompuSyn software (ComboSyn, Inc., Paramus, NJ, USA) was used to calculate the combination index (CI) (16). Briefly, the CI value was determined by the following equation: $\mathrm{CI}=\left(\Delta \mathrm{N}_{\mathrm{A}}+\Delta \mathrm{N}_{\mathrm{B}} / \Delta \mathrm{N}_{\mathrm{AB}}\right)$, where $\Delta \mathrm{N}_{\mathrm{A}}$ is the percentage decrease in viable cell number induced by compound $A, \Delta N_{B}$ is that induced by compound $\mathrm{B}$, and $\Delta \mathrm{N}_{\mathrm{A}}$ is that induced by their combination. The combination effect was judged as synergistic, additive or antagonistic when the CI was $<1,1$ and $>1$, respectively. 


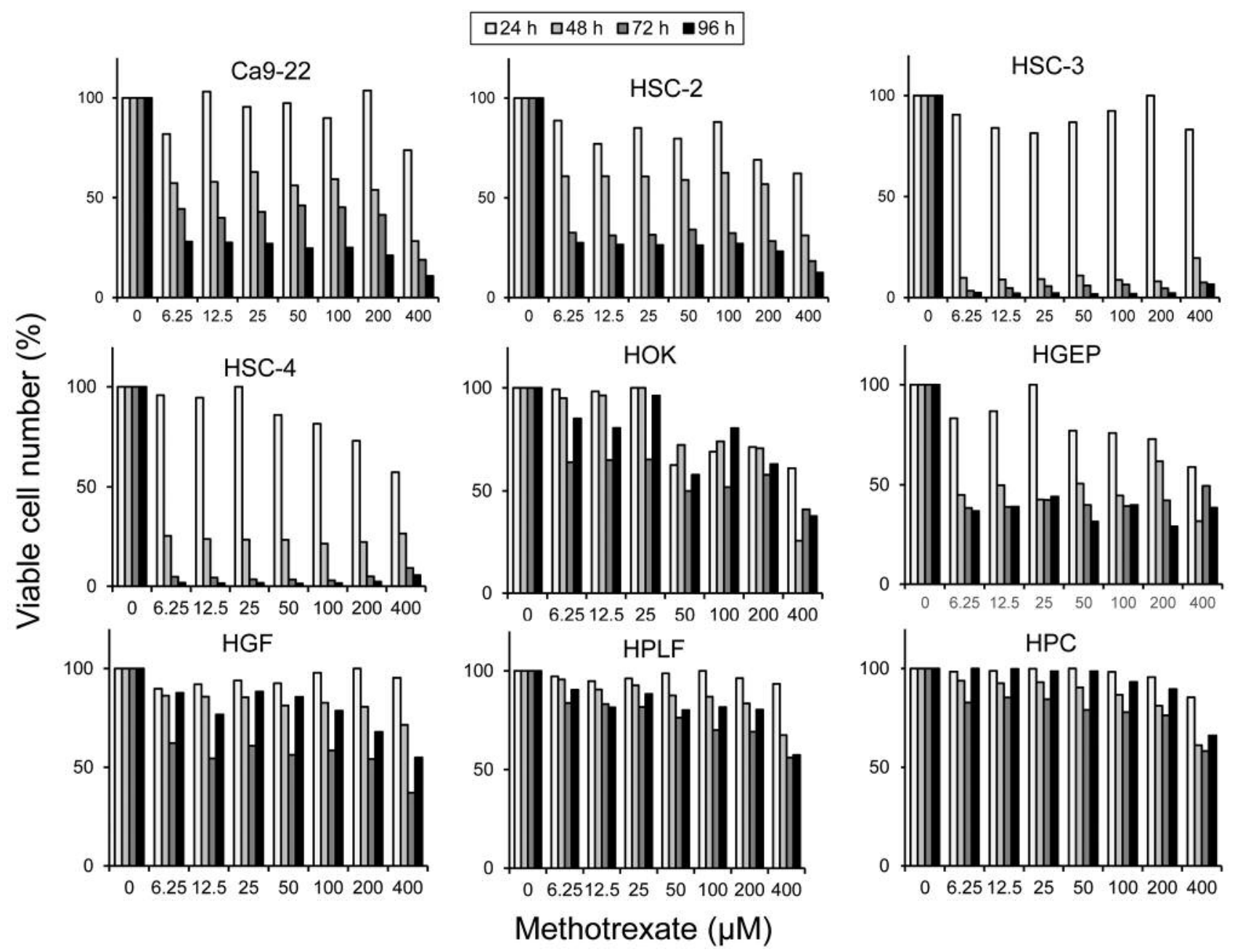

Figure 3. Time-dependent increase of cytotoxicity of methotrexate. A total nine different cells were inoculated at $2 \times 10^{3} /$ well in $96-$ microwell plate and incubated for $48 \mathrm{~h}$ to allow the complete cell attachment. Cells were then exposed for $48 \mathrm{~h}$ to the indicated concentrations of methotrexate to determine the viable cell number at $562 \mathrm{~nm}$ by MTT method. Each value represents mean of triplicate determinations. SD: $<10 \%$.

\section{Results}

Validity of the present method of TS evaluation. We first confirmed that the present assay system for TS evaluation reflects the actual anticancer activity of test samples. When HSC-2 cells were incubated for $24,48,72$ or $96 \mathrm{~h}$ without (control) or with $6.25,12.5,50,100,200$ or $400 \mu \mathrm{M}$ methotrexate, a popular antitumor agent, its cytotoxicity was increased with prolongation of treatment time (Figure 3). Methotrexate showed higher cytotoxicity against four human OSCC cell lines (Ca9-22, HSC-2, HSC-3, HSC-4) compared to human mesenchymal normal oral cells (HGF, HPLF and HPC). Human normal epithelial cells such HOK, and especially HGEP were very sensitive to methotrexate (Table I), confirming our previous report (14). Based on these data, we assayed the cytotoxicity of 10 alkylamino-guaiazulenes using four OSCC cell lines and three types of mesenchymal normal oral cells.

Cytotoxicity. When the length of the side chain alkyl group was increased, the cytotoxicity also increased (see compounds [1]-[5] in Figure 1); the $\mathrm{CC}_{50}$ decreased in the order [1], [2], [3], [4] and [5], [5] with six methylene groups was the most cytotoxic. Modified compounds of [5] with oxygen, nitrogen and sulfur atoms introduced into alkyl chains, such as compounds [6]-[9] showed slightly lower cytotoxicity. Compound [10] having a morpholine backbone showed much reduced cytotoxicity (Table II).

Tumor specificity. TS was determined by dividing the mean $\mathrm{CC}_{50}$ value towards three normal cells by the mean $\mathrm{CC}_{50}$ 

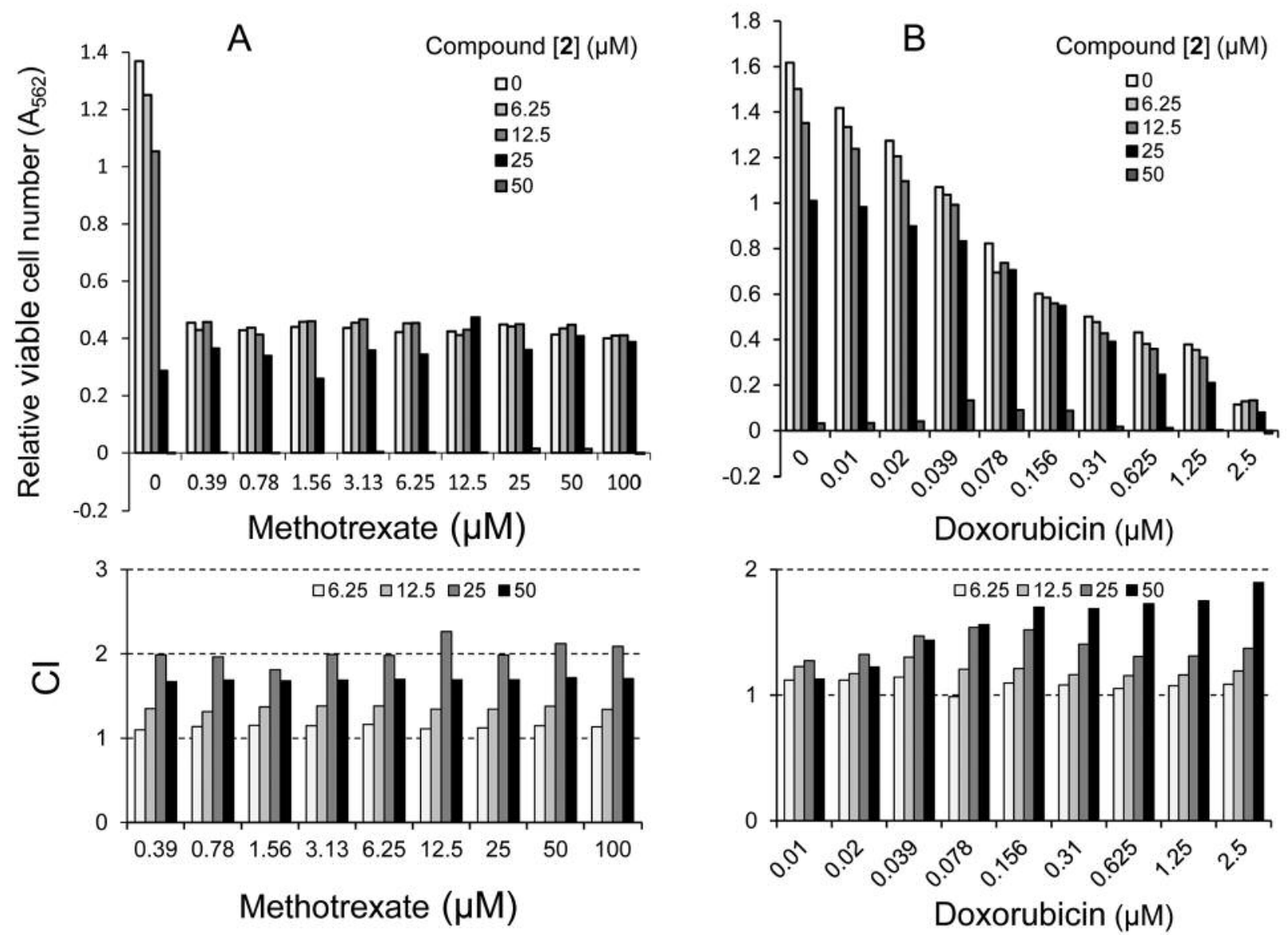

Figure 4. Antagonistic interaction of compound [2] and anticancer drugs. Near-confluent HSC-4 cells were incubated for $48 \mathrm{~h}$ with the indicated concentrations of methotrexate $(A)$ or doxorubicin $(B)$ in the presence of $0.6 .25,12.5,25$ or $50 \mu M$ of [2] and, then viable cell number was determined by the MTT method. Each value represents mean of triplicate assays. SD: $<10 \%$. From the dose-response curve, combination index (CI) was determined and plotted as a function of methotrexate or doxorubicin concentration.

A

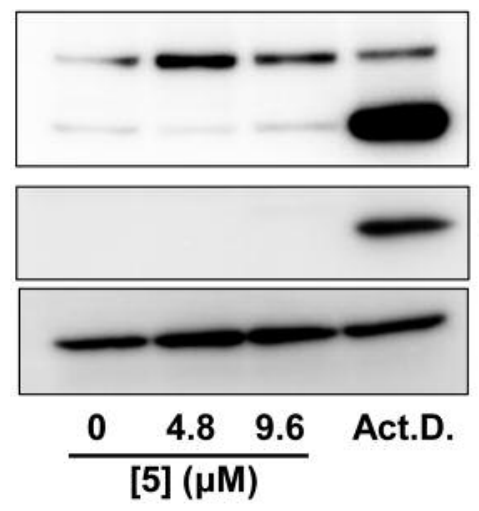

PARP

Cleaved PARP

Cleaved caspase-3

GAPDH

Figure 5. Induction of apoptosis by alkylaminoguaiazulenes in HSC-2 cells. Near-confluent HSC-2 cells were incubated for 24 h with the indicated concentrations of alkylaminoguaiazulenes and expression of cleaved products of poly ADP-ribose polymerase (PARP) and caspase-3 was visualized by western blot analysis. Each sample contains 0.1\% DMSO. Act.D., Actinomycin D $(1 \mu M)$, was used as a positive control for apoptosis. 


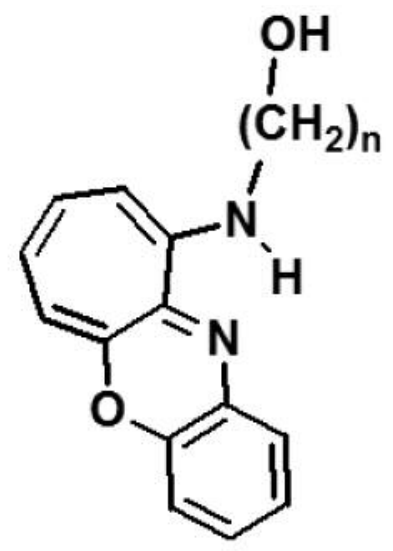

\begin{tabular}{cccr}
\hline & \multicolumn{3}{c}{$\mathrm{CC}_{50}(\mu \mathrm{M})$} \\
\cline { 2 - 3 } $\mathrm{n}$ & $\mathrm{Ca9}-22$ & HGF & TS \\
\hline 3 & $347.4 \pm 178.2$ & $>484.6 \pm 26.7$ & $>1.39$ \\
4 & $98.8 \pm 9.8$ & $154.2 \pm 35.8$ & 1.56 \\
5 & $98.9 \pm 18.3$ & $140.3 \pm 47.5$ & 1.42 \\
6 & $62.8 \pm 11.7$ & $134.2 \pm 31.0$ & 2.14 \\
\hline
\end{tabular}

Figure 6. Cytotoxicity of benzo[b]cyclohept[e][1,4]oxazines increases with increase in the chain length of alkyl group. n, Number of methylene units; TS, tumor selectivity index.

value towards four OSCC cell lines (D/B, Table I). Considering that HGF is the normal cell type corresponding to cancer cell Ca9-22 (both derived from gingival tissues), the TS value was also generated by dividing the average $\mathrm{CC}_{50}$ value for HGF cells by that for Ca9-22 cells (C/A, Table I). All 10 compounds showed very weak tumor specificity as compared with doxorubicin (TS=1.05 2.32 in $\mathrm{D} / \mathrm{B}$; $\mathrm{TS}=1.13 \sim 2.61 \mathrm{in} \mathrm{C} / \mathrm{A})$ (Table II).

Antagonistic action of alkylaminoguaiazulenes with anticancer drugs. Compound [2], having the highest TS value among compounds [1]-[5], did not enhance the cytotoxic activity of methotrexate or doxorubicin, as judged by the high $\mathrm{CI}(\mathrm{CI}>1)$ (Figure 4$)$.

Apoptosis induction. Compound [10], having the highest TS value among compounds [6]-[10], induced the cleavage of PARP and caspsase-3, suggesting the induction of apoptosis (Figure 5) (17).

\section{Discussion}

Ten alkylamino-guaiazulenes used here showed potent cytotoxicity against both cancer and normal cells, thus yielding very low tumor specificity $(\mathrm{TS}=1.05-2.29)$. Their cytotoxicity was increased with increasing length of the alkylamino group. This conclusion was further substantiated by our preliminary observation that cytotoxicity of benzo[ $b]$ cyclohept $[e][1,4]$ oxazines was increased with elongation of the methylene side chain (Figure 6), and none of them induced apoptosis (as assessed with DNA fragmentation and caspase activation experiments), like compound [5] demonstrated here.

We also found that [2], with the highest TS value among compounds [1]-[5] did not exhibit synergistic action with anticancer drugs (Figure 4). This reduces the possibility of clinical application of these compounds. However, we found that compound [10], with a morpholino group, led to apoptosis-inducing activity as well as higher TS values (Figure 5). This finding is in agreement with a recent report that various compounds having morpholine moieties had antiproliferative effect through $\mathrm{G}_{2} / \mathrm{M}$ cell-cycle arrest (18), apoptosis and autophagy induction (19) and high tumor specificity (20). The mechanism of induction of apoptosis and tumor specificity by $[\mathbf{1 0}]$ remains to be investigated.

\section{Conflicts of Interest}

The Authors confirm that there are no conflicts of interest associated with this publication and there was no significant financial support for this work that could have influenced its outcome.

\section{Acknowledgements}

This work was partially supported by KAKENHI from the Japan Society for the Promotion of Science (JSPS) (16K11519).

\section{References}

1 Li P, Liu X, Zhu H, Tang X, Shi X, Liu Y and Li G: Unusual inner-salt guaiazulene alkaloids and bis-sesquiterpene from the south china sea gorgonian muriceides collaris. Sci Rep 7(1): 7697, 2017.

2 Togar B, Turkez H, Hacimuftuoglu A, Tatar A and Geyikoglu F: Guaiazulene biochemical activity and cytotoxic and genotoxic effects on rat neuron and N2a neuroblastoma cells. J Intercult Ethnopharmacol 4(1): 29-33, 2015.

3 Fiori J, Teti G, Gotti R, Mazzotti G and Falconi M: Cytotoxic activity of guaiazulene on gingival fibroblasts and the influence of light exposure on guaiazulene-induced cell death. Toxicol In Vitro 25(1): 64-72, 2011.

4 Wakabayashi H, Hashiba K, Yokoyama K, Hashimoto K, Kikuchi H, Nishikawa H, Kurihara T, Satoh K, Shioda S, Saito S, Kusano S, Nakashima H, Motohashi $\mathrm{N}$ and Sakagami H: Cytotoxic activity of azulenes against human oral tumor cell lines. Anticancer Res 23(6C): 4747-4755, 2003.

5 Hannun YA: Apoptosis and the dilemma of cancer chemotherapy. Blood 89(6): 1845-1853, 1997.

6 Wakabayashi H, Kurihara T and Nozoe T: Synthesis and properties of tetraazaazulenocoronands and octaazaazulenocryptands. Heterocycles 54: 87-92, 2001. 
7 Mathias LJ and Overberger CG: Simple syntheses of 1,3bis(perfluoroacyl)azulenes and 1,3-azulenedicarboxylic acid. J Org Chem 45: 1701-1703, 1980.

8 Doukas PH and Speaker TJ: Azulene analogs of pharmacologic agents I: amides. J Pharm Sci 60: 184-189, 1971.

9 Kantoh K, Ono M, Nakamura Y, Nakamura Y, Hashimoto K, Sakagami $\mathrm{H}$ and Wakabayashi $\mathrm{H}$ : Hormetic and anti-radiation effects of tropolone-related compounds. In Vivo 24: 843-852, 2010.

10 Sakagami H, Shimada C, Kanda Y, Amano O, Sugimoto M, Ota S, Soga T, Tomita M, Sato A, Tanuma S, Takao K and Sugita Y: Effects of 3-styrylchromones on metabolic profiles and cell death in oral squamous cell carcinoma cells. Toxicol Rep 2: 1281-1290, 2015.

11 Sakagami H, Uesawa Y, Ishihara M, Kagaya H, Kanamoto T, Terakubo S, Nakashima H, Takao K and Sugita Y: Quantitative structure-cytotoxicity relationship of oleoylamides. Anticancer Res 35: 5341-5355, 2015.

12 Uesawa Y, Sakagami H, Kagaya H, Yamashita M, Takao K and Sugita Y: Quantitative structure-cytotoxicity relationship of 3benzylidenechromanones. Anticancer Res 36(11): 5803-5812, 2016.

13 Horikoshi M, Kimura Y, Nagura H, Ono T and Ito H: A new human cell line derived from human carcinoma of the gingiva. I. Its establishment and morphological studies. Jpn J Oral Maxillofac Surg 20: 100-106, 1974.

14 Sakagami H, Okudaira N, Masuda Y, Amano O, Yokose S, Kanda Y, Suguro M, Natori T, Oizumi H and Oizumi T: Induction of apoptosis in human oral keratinocyte by doxorubicin. Anticancer Res 37(3): 1023-1029, 2017.

15 Tomikoshi Y, Nomura M, Okudaira N, Sakagami H and Wakabayashi H: Enhancement of cytotoxicity of three apoptosisinducing agents against human oral squamous cell carcinoma cell line by benzoxazinotropone. In Vivo 30(5): 645-650, 2016
16 Sugimori N, Espinoza JL, Trung LQ, Takami A, Kondo Y, An DT, Sasaki M, Wakayama T and Nakao S: Paraptosis cell death induction by the thiamine analog benfotiamine in leukemia cells. PLoS One 10(4): e0120709, 2015.

17 Bressenot A, Marchal S, Bezdetnaya L, Garrier J, Guillemin F and Plénat F: Assessment of apoptosis by immunohistochemistry to active caspase-3, active caspase-7, or cleaved PARP in monolayer cells and spheroid and subcutaneous xenografts of human carcinoma. J Histochem Cytochem 57(4): 289-300, 2009.

18 Diao PC, Li Q, Hu MJ, Ma YF, You WW, Hong KH and Zhao PL: Synthesis and biological evaluation of novel indolepyrimidine hybrids bearing morpholine and thiomorpholine moieties. Eur J Med Chem 134: 110-118, 2017.

19 Rahman FU, Ali A, Khan IU, Duong HQ, Yu SB, Lin YJ, Wang $\mathrm{H}, \mathrm{Li}$ ZT and Zhang DW: Morpholine or methylpiperazine and salicylaldimine based heteroleptic square planner platinum (II) complexes: In vitro anticancer study and growth retardation effect on E. coli. Eur J Med Chem 131: 263-274, 2017.

20 Yamali C, Gul HI, Sakagami H and Supuran CT: Synthesis and bioactivities of halogen bearing phenolic chalcones and their corresponding bis Mannich bases. J Enzyme Inhib Med Chem 31(sup4): 125-131, 2016.
Received January 29, 2018

Revised March 8, 2018

Accepted March 15, 2018 